\title{
Yoğurt Örneklerinden İzole Edilmiş Laktik Asit Bakterilerinin Moleküler Yönt- emlerle Tanımlanması ve Ekzopolisakkarit Üretimlerinin Belirlenmesi
}

\author{
Ebru DEMIR ${ }^{1}$, Evrim KAYGUSUZ ${ }^{2}$, Gülden BAŞYIĞiT KILIÇ ${ }^{3 *}$, Sedef YÜCE ${ }^{1}$, Ali SOYUÇOK ${ }^{4}$ \\ ${ }^{1}$ Mehmet Akif Ersoy Üniversitesi, Fen Bilimleri Enstitüsü, Burdur \\ ${ }^{2}$ Sedaca Mutfak Sanatları, İzmir \\ ${ }^{3}$ Mehmet Akif Ersoy Üniversitesi, Mühendislik Mimarlık Fakültesi, Burdur \\ ${ }^{4}$ Süleyman Demirel Üniversitesi, Fen Bilimleri Enstitüsü, Isparta \\ Geliş Tarihi (Received): 15.11.2017, Kabul Tarihi (Accepted): 10.12.2017 \\ $\square$ Sorumlu Yazar (Corresponding author*): gkilic@mehmetakif.edu.tr \\ (C) +902482132724 且 +902482132704
}

ÖZ

Laktik asit bakterileri (LAB) fermente gıda endüstrisinde önemli bir role sahiptir. Özellikle LAB yoğurt üretimi için önem arz ederler. Yoğurtta LAB yapıyı, viskoziteyi ve su tutma kapasitesini geliştirir. Ekzopolisakkarit (EPS) üreten $L A B$ fermente süt ürünlerinin kıvam ve reolojik özelliklerine katkıda bulunduğu için süt ürünleri endüstrisinde önemlidir. Bu çalışmada daha önceden Akdeniz bölgesindeki ev veya küçük ölçekli işletmelerde geleneksel yöntemlerle üretilmiş kırk adet yoğurt örneğinden izole edilmiş 55 adet laktik asit bakterisinin (LAB) genetik tanımlamaları yapılmıştır. 16S-ITS rRNA geni Polimeraz Zincir Reaksiyonu (PZR) ile çoğaltılmıştır. Taql ve Haelll kesim enzimleri çoğaltılmış DNA'nın kesilmesinde kullanılmıştır. Tüm bakterilere DNA sekans analizi yapılmış ve elde edilen sekanslar BLAST programı kullanılarak Gen Bankasında kayıtı dizilerle karşılaştııımışı.ı. Bakterilerin ekzopolisakkarit (EPS) üretimleri belirlenmiştir. Bakterilerin 16S-ITS RFLP analizi tanı testi sonuçlarına göre ise; 6 adet bakteri Lactobacillus delbrueckii subsp. bulgaricus (L. bulgaricus) olarak tanımlanmıştır. Tanı testi sonuçlarına göre; bakterilerin 50 tanesi L. bulgaricus, 2'şer tanesi Lactobacillus helveticus ve Enterococcus faecium, 1 tanesi Pediococcus acidilactici olarak tanımlanmıştır. Bakterilerin EPS üretim miktarları 5,89 ile $134,60 \mathrm{mg} / \mathrm{L}$ arasında tespit edilmiştir. Araştırma neticesinde L. bulgaricus La24B, La38A, La4C, Lj40C, La14A ve Lj38A'nın en iyi EPS üreten suşlar olarak tespit edilmiştir.

Anahtar Kelimeler: Ekzopolisakkarit,16S-ITS rRNA, yoğurt, başlatıcı kültür

\section{Molecular Identification of Lactic Acid Bacterial Solated from Yoghurt Sam- ples and Determination of Exopolysaccharide Production Properties}

\begin{abstract}
Lactic acid bacteria (LAB) have an important role in fermented food industry. Especially, LAB is essential for yoghurt production. In yoghurt LAB improve structure, viscosity and water holding capacity. LAB that produce exopolysaccharides (EPS)s are important in the dairy industry because of their contribution to the consistency and rheology of fermented milk products. In this study, a 55 LAB previously isolated from forty yoghurt samples produced by traditional methods in homes or small scale dairy plants in Mediterranean region were used for genotyping characterization. The 16S-ITS rRNA gene was amplified by Polymerase Chain Reaction (PCR). Taql and Haelll restriction enzymes
\end{abstract}


were used for restriction digest of the amplified DNA. DNA sequencing was performed to all bacteria and the sequences obtained were then evaluated in GenBank using BLAST programme. EPS production properties of the bacteria were also investigated. According to 16S-ITS RFLP analyses 6 bacteria were identified as Lactobacillus delbrueckii subsp bulgaricus ( $L$. bulgaricus). According to sequence analyses of the isolates, it was found that the most common LAB species in yoghurt samples were 50 L. bulgaricus strains, 2 Lactobacillus helveticus strains, 2 Enterococcus faecium strains, 1 Pediococcus acidilactici strain and 1 Enterococcus faecium strain were also identified. The amount of EPS in bacteria was determined between 5,89 and $134,60 \mathrm{mg} / \mathrm{L}$. The results showed that $L$. bulgaricus La24B, La38A, La4C, Lj40C, La14A ve Lj38A were the best EPS-producing strains.

Keywords: Exopolysaccharide, 16S-ITS rRNA, yoghurt, starterculture

\section{GíRiş}

Sağlığa yararlı etkileri ve fermantasyon reaksiyonlarında önemli fonksiyonları olan LAB'ler gıda endüstrisinde kullanılan bakterilerin en önemlileri arasındadır (Yerlikaya, 2014). Bu bakteriler hayvanlarda ve insanlarda, özellikle gençlerde, sindirim sisteminde önemli role sahiptirler. Bu bakterilerin fermantasyon, biyolojik işlemler, ziraat, gıda ve özellikle son zamanlarda tıp alanında önemlerinin anlaşılmasıyla birlikte yapılan çalışmalar yoğunlaşmıştır.

LAB'nin kesin olarak tanımlanmaları teknolojik, ekolojik ve güvenlik açısından büyük önem taşımaktadır (Yerlikaya, 2014). Laktobasillerin gıda üretiminde kullanılabilmeleri için öncelikle tür düzeyinde tanımlamalarının yapılması gerekmektedir. LAB tanımlanmalarında geleneksel olarak kullanılan taksonomik sınıflandırmanın temeli fizyolojik, morfolojik ve farklı sıcaklıklarda, $\mathrm{pH}$ değerlerinde, tuz konsantrasyonlarında gelişme, arjinindegredasyonu ve karbonhidrat katabolizması gibi metabolik/biyokimyasal özelliklerin incelenmesini içeren fenotipik özelliklere dayanmaktadır (Kandler ve Weiss, 1986; Gobbetti ve ark., 2005). LAB'nin çoğu oldukça benzer besinsel intiyaçlara sahip olup, benzer çevresel şartlar altında gelişim gösterebildikleri için tür düzeyinde tanımlanmalarında kullanılan bazı geleneksel yöntemler oldukça zaman alıcı ve aynı zamanda ayrım gücü ve hassasiyetleri bakımından da kısmen güvenilirdir. Ayrıca gelişme koşulları hücre morfolojisini etkileyebilmekte ve bazı durumlarda cins düzeyinde dahi tanımlama işlemlerinde zorluk yaratmaktadırlar (Kıran ve Osmanağaoğlu, 2011). Bu sebeple, son yıllarda çalışmalar gıda kökenli LAB'nin mikrobiyal identifikasyonları için moleküler tekniklerin kullanılması üzerine yoğunlaşmıştır.

Moleküler tanımlama yöntemleri, gelişmekte olan teknolojinin mikrobiyoloji alanında sunduğu en önemli yeniliklerden biridir (Çetinkaya ve Ayhan, 2012). LAB'nin tanımlanmasında 16S rDNA veya 235 rDNA'yı hedef alan primerlerden yararlanılan Polimeraz Zincir Reaksiyonu (PZR)'na dayalı yöntemler, araştırılan Lactobacillus türlerinin tanımlanmasında başarılı bir şekilde kullanılmaktadır.
Son dönemlerde tüketiciye katkı maddesi içermeyen sağlıklı ve kaliteli ürünler sunmak amacıyla bitkisel kökenli polisakkaritlere alternatif olarak EPS üreten LAB'den yararlanılmaktadır. LAB, hücre içerisinde polisakkarit oluşturmakta ve bunlardan hücre dışına salgılananlara EPS denilmektedir (Ruas-Madiedo ve ark., 2002). EPS hem son ürünün tekstürünü ve reolojik özelliklerini geliştirerek, hem de su bağlayarak stabilizatör olarak sinerezisi sınırlandırır. EPS polimerlerinin; fiziksel ve teknolojik özellikleri kimyasal kompozisyonu, moleküler büyüklüğüne, miktarına, dallanmış yapılarına, molekül sertliğine ve üç boyutlu yapısına bağlı olarak değişmektedir. Fiziksel karakteristiklerine ilaveten EPS ve çeşitli yapılar arasındaki etkileşimler son ürünün gelişmesine katkı sağlarlar. LAB tarafından üretilen EPS'ler genellikle süt sanayisinde fermente ürünün teknolojik özelliklerinin geliştirilmesinde ve fonksiyonel ürünün üretilmesi için kullanılır (Werning ve ark., 2012). Bu yüzden yapılan çalışmalar, fermente süt ürünlerinin reolojik özellikleri ve bu bakterilerin ürettikleri EPS miktarı ile ilişkilendirilmiştir (de Vuyst ark., 2001; Duboc ve Mollet, 2001; Folkenberg ve ark., 2006).

Gıda reçetelerine giren bileşenler arasında fonksiyonel role sahip olan maddelerin ilavesi veya mevcut olanlarla yer değiştirmesi son derece önemlidir. Buna bağlı olarak da fermente süt ürünlerinin üretiminde EPS üreten LAB'nin kullanımı giderek artmaktadır. EPS'ler süt sanayisinde; gıda katkı maddesinin kullanımını azaltmak, yoğurdun viskozitesini geliştirmek, yapıyı ve aromayı iyileştirmek, fermantasyon süresi boyunca ve depolama sırasında sinerezisi önlemek ayrıca tekstürün oluşmasında, lezzetin algılanmasında ve istenilen yapının oluşmasında temel rol oynar (Patel ve Prajapati, 2013).Yapılan bu araştırmada ülkemizin farklı illerinden ancak çoğunlukla Burdur, Isparta ve Antalya piyasasından, özellikle halk pazarlarından toplanmış ev, mandıra veya küçük ölçekli işletmelerde geleneksel olarak üretilmiş olan yoğurt örneklerinden izole edilmiş LAB'i moleküler yöntemlerle tanımlanarak, EPS üretimleri belirlenmiştir. 


\section{MATERYAL VE YÖNTEM}

Farklı illerdeki halk pazarlarından toplanan, özellikle evlerde ve mandıralarda küçük ölçekli, geleneksel yöntemlerle üretilmiş farklı çeşitteki 40 adet yoğurt örneğinden farklı besiyerleri kullanılarak izole edilmiş kok ve çubuk şekilli, sporsuz, Gram pozitif, katalaz reaksiyonu negatif olan 55 adet LAB kullanılmıştır (Akpınar, 2013 basılmamış veri).

\section{İolatların Genetik Tanısının Yapılması}

16S rRNA analizi izolatların genomik DNA'ları ticari DNA ekstraksiyon kiti (PureLinkGenomic DNA Kit, Invitrogen K) kullanılarak, kullanma kılavuzunda belirtildiği şekilde ekstrakte edilmiştir. Elde edilen DNA $75 \mu \mathrm{lyl}$ kama çözeltisi içerisinde toplanıp $-20^{\circ} \mathrm{C}$ 'de saklanmıştır.16S-ITS bölgesi forwardprimer (Mora ve ark., 1998) ve reversprimer (Jensen ve ark., 1993) kullanılarak 1800-2000 bp gen bölgesinde çoğaltılmıştır. PZR reaksiyonu için 1 örneğe toplamda $50 \mu$ l olacak şekilde $5 \mu \mathrm{l}$ genomik DNA, $5 \mu \mathrm{l} 10 \times \mathrm{KCl}$ reaksiyon buffer(Fermentas, ThermoFisherScientific, ABD), $3 \mu \mathrm{l}$ $\mathrm{MgCl}_{2} \quad(25 \mathrm{mM})$ (Fermentas, ThermoFisherScientific, ABD), $30 \mu \mathrm{l}$ steril $\mathrm{dH} 20,1 \mu \mathrm{l}$ ileri primer $(10 \mathrm{mM}), 1 \mu \mathrm{l}$ geri $(10 \mathrm{mM}), 5 \mu \mathrm{d}$ dNTPkarışımı (her biri $2 \mathrm{mM}$ ) (Fermentas, Thermo Fisher Scientific, ABD), $0.24 \mu \mathrm{l} \mathrm{Taq}$ DNA polimeraz (Fermentas, Thermo Fisher Scientific, $A B D)$ hazırlanmıştır. Bu karışımın termal döngü cihazı (Bio-Rad T100, ABD) kullanılarak; 5 dakika boyunca $94^{\circ} \mathrm{C}$ 'de, 1 dakika 40 döngüde $94^{\circ} \mathrm{C}$ 'de denatürasyon, 1 dakika $42^{\circ} \mathrm{C}$ 'de bağlanma, 1 dakika $72^{\circ} \mathrm{C}$ 'de uzama ve 10 dakika $72^{\circ} \mathrm{C}$ 'de son uzaması gerçekleştirilmiştir. PZR ürünleri \%1'lik agaroz jelinde yürütülerek UV ışık altında görüntülenmiştir.

$P Z R$ ürünlerinin temizlenmesi amacıyla $P Z R$ ürünlerinin hacmi 1x Tris-EDTA (TE) tamponu ile $100 \mu$ l'ye tamamlanmıştır. Örnekler steril eppendorf tüplerine aktarılarak üzerlerine iki hacim kadar $(200 \mu \mathrm{l})$ kloroform-izoamil alkol (24 kloroform:1 izoamil alkol) eklendikten sonra $15-20$ saniye vortex ile karıştırılmış ve 10,000 rpm'de 2 dakika santrifüjlenmiştir. Kloroform fazı (alt faz) uzaklaştırıldıktan sonra, kloroform, karıştırma ve santrifüj aşamaları tekrarlanmıştır. Örnek fazı (üst faz) yeni eppendorf tüplerine toplanmıştır. 1/10 örnek hacmi (10 $\mu \mathrm{l})$ kadar 3M sodyum asetat ( $\mathrm{pH}$ 5.2) eklenip karıştırılmıştır. Üzerine 2.5 örnek hacmi $(275 \mu \mathrm{l}) \% 100$ etanol (moleküler biyoloji saflıkta) eklenerek, 15-20 saniye karıştırılmıştır. 15 dakika 14,000 rpm'de santrifüjlenip, sıvı kısım pelletin yapıştığı duvarın ters tarafından toplanmıştır. Tüplere $300 \mu \mathrm{l} \% 70$ etanol eklenip 20 saniye karıştırılmıştır.5 dakika 14,000 rpm'de santrifüjledikten sonra sıvı kısım dikkatlice uzaklaştırılıp, pelletler $37^{\circ} \mathrm{C}$ 'lik inkübatörde $15-20$ dakika kurutulmuştur. Pel- letler $20 \mu \mathrm{l}$ 1xTE içerisinde çözündürülerek $-20^{\circ} \mathrm{C}$ 'de muhafaza edilmiştir.

PZR ürünlerinin kesilmesi için $10 \mu \mathrm{l}$ temizlenen PZR ürünü, $5 \mu \mathrm{l} 10 \mathrm{x}$ restriksiyon enzimi tamponu, $34.5 \mu \mathrm{l}$ steril $\mathrm{dH}_{2} \mathrm{O}, 5 \mathrm{U}(0.5 \mu \mathrm{l})$ Taql eklenerek hacim $50 \mu \mathrm{l}$ 'ye tamamlanmıştır. Tüplerin üzerlerine 2 damla mineral yağ damlatılıp, tüplerin kapakları parafilm ile sarılarak $65^{\circ} \mathrm{C}$ 'de 1 gece su banyosunda inkübe edilmiştir. Aynı reaksiyon $5 \mathrm{U}$ HaellI için de uygulanmıştır. Bu reaksiyon için inkübasyon $37^{\circ} \mathrm{C}$ 'de gerçekleştirilmiştir. Kesim örnekleri PZR ürünlerinin temizlenmesi bölümünde anlatıldığı şekilde temizlenmiş, örnekler son olarak 10 $\mu \mathrm{l}$ 1x TE içerisinde çözündürülmüştür (Sudağıdan, 2007; Udomsil ve ark., 2010).

\section{Restriksiyon Parça Uzunluk Polimorfizmi (RFLP)}

Kesilen ve temizlenen PZR ürünleri \%2'lik Tris-asetatEDTA (TAE) agaroz jeli hazırlanarak $10 \mu \mathrm{l}$ kesim ürünü ve $2 \mu \mathrm{l}$ 6X Dye yükleme boyası eklenerek yürütülmüştür. Illk aşamada 1 saat $40 \mathrm{~mA}$ bunu takiben 3 saat 60 mA sabit akım uygulanmıştır. Jel'e $5 \mu 100$ bp DNA marker'ı (500 ng DNA) (Fermentas) yüklenmiştir. DNA'ların yürümesi tamamlandığında agaroz jeli bir kaba alınmış ve etidyum bromür ile boyanmıştır. Bu amaçla $200 \mu \mathrm{l}$ etidyum bromür $(10 \mathrm{mg} / \mathrm{ml}) 1$ litre deiyonize su ile karıştııılarak 30 dakika çalkalayıcıda düşük devirde karıştırılmıştır. 30 dakika sonunda etidyum bromür solüsyonu boşaltılarak jeli kaplayacak kadar deiyonize su eklenip 30 dakika çalkalanmıştır. Elde edilen bant paterni UV ışık altında görüntülenip jel dökümantasyon sistemi kullanılarak band patternleri referans suşlar ile karşılaştırılmış Image Lab3.0, EZDoc Image Analyser (Bio-Rad) ile analiz edilmiştir.

\section{Dizi Analizi}

Çalışmada 55 bakterinin tamamına dizi analizi yapılmıştır. Bakterilerin dizi analizi İzmir Yüksek Teknoloji Ensitütüsü, Biyoteknoloji ve Biyomühendislik Uygulama ve Araştırma Merkezi'nde yaptırılmıştır. Bu amaçla çoğaltılmış 16S rRNA PZR ürünleri (5'AGAGTTTGATCCTGGCTCAG-3' ve 5'CTACGGCTACCTTGTTACGA-3') primerleri kullanılarak AppliedBiosystems 3130xI Genetic Analyzer cihazı ile çalışılmıştır. Elde edilen elektroferogramlar FinchTV ve BioEditsoftware programı kullanılarak analiz edilmiş ve DNA dizileri NucleotideBlast (http://blast.ncbi.nlm.nih.gov) kullanılarak karşılaştııılmıştır.

\section{Bakterilerde EPS Üretiminin Belirlenmesi}

EPS miktarının belirlenmesi amacıyla MRS besiyerinde $37^{\circ} \mathrm{C}$ 'de geliştirilmiş 18 saatlik kültür su banyosunda 15 
dakika kaynatılmıştır. Kültür oda sıcaklığına soğutulduktan sonra 1,5 ml'lik santrifüj tüpüne $1 \mathrm{ml}$ örnek alınıp, üzerine $900 \mu \mathrm{l} \% 85^{\prime}$ lik TCA (Triklorasetik asit, Molekula, Ingiltere) ilave edilmiştir. 13000 x g'de 25 dakika santrifüjleme işleminden sonra, süpernatant uzaklaştırılmış ve etil alkol (Merck, Almanya) ilave edilip tekrar santrifüjlenmiştir. Bu işlem 2 kere tekrarlanmıştır. Santrifüjleme sonunda etanol hızlıca ve dikkatlice uzaklaştırılmıştır. Pellet $1 \mathrm{ml}$ ultra saf su içerisinde çözündürülmüştür. EPS miktarını belirlemek için glukoz (Merck, Almanya) standart kurvesi ile fenol-sülfirik asit yöntemi kullanılmıştır. $0,1 \mathrm{~g}$ glukoz $1 \mathrm{~L}$ ultra saf su içerisinde çözündürülmüştür. Kurve çizmek için glukoz-su karışımından $1 \mathrm{ml}$ alınıp 15 ml'lik santrifüj tüpüne aktarılmıştır. Örneğin üzerine önce $0,5 \mathrm{ml} \% 5^{\prime}$ lik fenol çözeltisi ilave edildikten sonra dikkatlice $5 \mathrm{ml}$ sülfirik asit (Merck, Almanya) ilave edilmiştir. Tüpler $30^{\circ} \mathrm{C}$ 'de 20 dakika bekletildikten sonra, $490 \mathrm{~nm}$ 'de absorbans değeri ölçülmüş (T8+ UVIVIS Spectrometer, PG Instruments Ltd. İngiltere),EPS miktarı glukoz cinsinden (mglL) hesaplanmıştır (Dubois ve ark., 1956).

\section{BULGULAR VE TARTIŞMA}

16S-ITS RFLP analizi tanı testi sonuçlarına göre; Lc33A, Lc34A, Lj17C, Lj19B, Lj35A ve Lj36A2 kodlu bakteriler $L$. bulgaricus olarak tanımlanmış (Şekil1), diğer bakteriler tam olarak gruplandırılamamıştır. Bu sebeple bakterilerin tamamına sekans analizi yaptırılmıştır. Bakteriler 16S rRNA dizi analizinden elde edilen baz sıralarının NCBI BLAST veri tabanındaki sonuçlarına göre; 50 adet $L$. bulgaricus, 2'şer adet $L$. helveticus ve $E$. faecium, 1 adet $P$. acidilactici olarak tanımlanmıştır (Tablo 1).

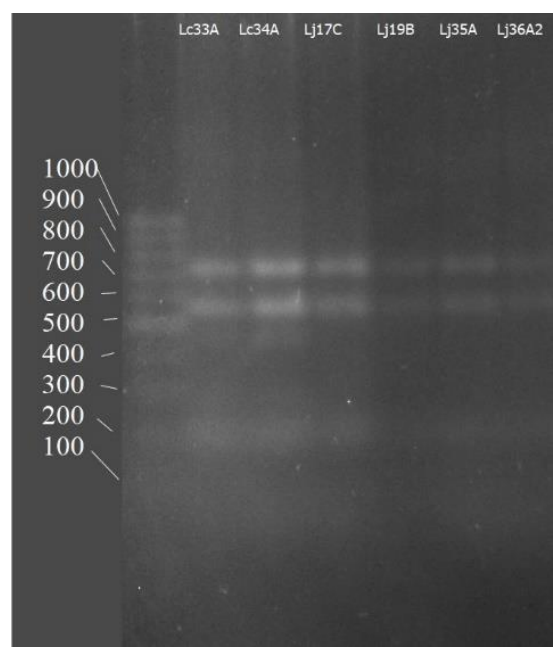

Şekil 1. PZR ürünlerinin Haelll kesim enzimi uygulaması sonucu elde edilen agaroz jel görüntüsü
LAB'nin endüstriyel uygulamaları düşünüldüğünde, araştırmaların en temel amacı kullanılabilecek olan LAB suşlarının seçimidir. Bu nedenle, herhangi bir suşun spesifik ve belirgin olarak ayrımını sağlayan güvenilir yöntemlerin uygulanması oldukça önemlidir (Kıran ve Osmanağaoğı, 2011). Kok ve Venema (1998), istenilen kalitede süt ürünlerinin elde edilebilmesi için, proteolitik aktivitesi yüksek, hızlı asit üreten LAB'ye gerek duyulduğunu ve bu bakterilerle yapılan genetik çalışmaların artırılması, ayrıca klonlama sistemlerinin geliştirilmesinin gerektiğini savunmuşlardır. Lee ve Kim (1986), kefir tanelerinden izole ettikleri 90 adet bakteriyal suşun karakterizasyonunu çalışmışlar ve suşların \%40-60'ının L. brevis ve L. buchneri olduğunu bildirmişlerdir. Araştırmacılar laktokok izole edememişlerdir. Söz konusu çalışmamızda incelenen izolatlar arasında laktokok tespit edilmemiştir. Yüksekdağ ve Beyatı (2009)'nın yapmış olduğu bir çalışmada ise, Türkiye orijinli kefirlerden 13 adet $L A B$ izole edilmiştir. Biyokimyasal testler ve API CH 50 kitlerinin kullanılmaları sonucunda izolatlar, $L$. helveticus ( 3 adet), L. brevis (1 adet), L. casei (1 adet), L. lactis (1 adet), Str. thermophilus (2 adet), E. durans (1 adet), L. cremoris ( 3 adet) ve $L$. lactis (1 adet) olarak tanımlanmıştır.

Bakterilerin EPS üretim miktarları 5,89 ile 134,60 mg/L arasında tespit edilmiştir. Yapılan çalışma sonucunda en yüksek EPS üretimi glukoz cinsinden (mglL) $L$. bulgaricus La24B (134,60), La38A (116,23), La4C (111,78 $\mathrm{mg} \backslash \mathrm{L})$, Lj40C $(107,03)$, La14A $(101,29)$ ve Lj38A $(97,55)$ 'da, en düşük EPS üretimi ise $L$. bulgaricus Lc7E $(5,89)$ 'de belirlenmiştir. Van Geel- Schutten ve ark. (1998) tarafından yapılan çalışmada EPS üretimleri incelenen 182 adet Lactobacillus suşundan 60 tanesinin EPS ürettiği, bunlardan 17 suşun EPS üretiminin $100 \mathrm{mg} / \mathrm{L}$ 'den fazla olduğu belirtilirken, EPS üretimi için en uygun bileşenin sakkaroz olduğu kaydedilmiştir. Faber ve ark. (1998) Str. thermophilusRs ve Str. thermophilusSt suşları tarafından $135 \mathrm{mg} / \mathrm{L}$ ve $127 \mathrm{mg} / \mathrm{L}$ EPS üretildiğini belirtmiştir. Yaptığımız çalışma sonucunda yoğurtlardan izole edilen 55 adet Lactobacillus suşunun tamamının glukoz cinsinden EPS ürettiği ve 5 suşun EPS üretiminin $100 \mathrm{mg} / \mathrm{L}$ 'den fazla olduğu belirlenmiştir. 
Yoğurt Örneklerinden İzole Edilmiş Laktik Asit Bakterilerinin Moleküler Yöntemlerle Tanımlanması ve Ekzopolisakkarit Üretimlerinin Belirlenmesi 
Tablo 1. 16S rRNA dizi analizine göre bakterilerin tanı testi sonuçları

\begin{tabular}{|l|l|}
\hline $\begin{array}{l}\text { 16S rRNA dizi analizine göre tanı } \\
\text { testi sonuçları }\end{array}$ & Suş No: \\
\hline $\begin{array}{l}\text { Lactobacillus delbrueckii subsp. } \\
\text { bulgaricus }\end{array}$ & La3C, La4C, La7C, La14A, La15A, La17B, La21C, La24B, La25A, La26A, La30A, \\
& La32A, La33B, La34B, La38A, La39B, La40A, Lb24C, Lb25B, Lc7e, Lc14B, Lc18C, \\
& Lc25A, Lc28A, Lc33A, Lc34A, Lr14A, Lr14B, Lr17D, Lr20C, Lr21B, Lr28A, Lr28B, \\
& Lr34A, Lr39A, Lr41, Lr47A, Lr48, Lj17C, Lj18B, Lj19B, Lj23C, Lj24A, Lj30A, Lj35A, \\
\hline Lactobacillus helveticus & Lj36A2, Lj37B, Lj38A, Lj40C, St17D \\
\hline Pediococcus acidilactici & St22B, St27CB \\
\hline Enterococcus faecium & La19B \\
\hline
\end{tabular}

Tablo 2. Bakterilerin EPS üretim miktarları

\begin{tabular}{|c|c|c|c|c|c|}
\hline $\begin{array}{l}\text { 16S rRNA dizi } \\
\text { analizine göre } \\
\text { tanı testi sonuç- } \\
\text { ları örnek adı }\end{array}$ & $\begin{array}{l}\text { EPS Miktarı } \\
\text { Glukoz Cinsin- } \\
\text { den (mg } \mathrm{L} \text { ) }\end{array}$ & $\begin{array}{l}\text { 16S rRNA dizi } \\
\text { analizine göre } \\
\text { tanı testi sonuç- } \\
\text { ları örnek adı }\end{array}$ & $\begin{array}{l}\text { EPS Miktarı } \\
\text { Glukoz Cinsin- } \\
\text { den }(m g \backslash L)\end{array}$ & $\begin{array}{l}\text { 16S rRNA dizi } \\
\text { analizine göre } \\
\text { tanı testi sonuç- } \\
\text { ları örnek adı }\end{array}$ & $\begin{array}{l}\text { EPS Miktarı } \\
\text { Glukoz Cinsin- } \\
\text { den (mg\L) }\end{array}$ \\
\hline LbLa3C & 71,98 & LbLc7E & 5,89 & LbLj17C & 35,12 \\
\hline LbLa4C & 111,78 & LbLc14B & 38,40 & LbLj18B & 17,18 \\
\hline LbLa7C & 36,38 & LbLc18C & 16,18 & LbLj19B & 64,98 \\
\hline LbLa14A & 101,29 & LbLc25A & 15,60 & $L b \mathrm{Lj} 23 \mathrm{C}$ & 39,76 \\
\hline LbLa15A & 14,49 & LbLc28A & 88,51 & $L b \mathrm{Lj} 24 \mathrm{~A}$ & 54,83 \\
\hline LbLa17B & 25,75 & $\angle b L c 33 A$ & 29,54 & $L b \mathrm{Lj} 30 \mathrm{~A}$ & 70,56 \\
\hline LbLa21C & 77,48 & $\angle b L c 34 A$ & 19,12 & $L b \mathrm{Lj} 35 \mathrm{~A}$ & 72,46 \\
\hline LbLa24B & 134,60 & LbLr14A & 42,98 & LbLj36A2 & 87,96 \\
\hline LbLa25A & 23,49 & LbLr14B & 62,80 & LbLj37B & 34,32 \\
\hline LbLa26A & 21,07 & LbLr17D & 35,12 & LbLj38A & 97,55 \\
\hline LbLa30A & 30,03 & LbLr20C & 56,68 & LbLj40C & 107,03 \\
\hline LbLa32A & 18,52 & LbLr21B & 53,25 & LbSt17D & 39,06 \\
\hline LbLa33B & 29,90 & LbLr28A & 58,99 & Lh St22B & 27,12 \\
\hline LbLa34B & 70,09 & LbLr28B & 73,64 & Lh St27CB & 87,34 \\
\hline LbLa38A & 116,23 & LbLr34A & 25,92 & PaLa19B & 42,29 \\
\hline LbLa39B & 36,73 & LbLr39A & 53,24 & EALr13A & 79,48 \\
\hline LbLa40A & 77,99 & LbLr41 & 64,56 & Eflc13B & 60,75 \\
\hline LbLb24C & 20,22 & LbLr47A & 64,74 & & \\
\hline LbLb25B & 18,80 & LbLr48 & 76,42 & & \\
\hline
\end{tabular}

Lb (Lactobacillus delbrueckii subsp. bulgaricus), Lh (Lactobacillus helveticus), Pa (Pediococcus acidilactici),Ef (Enterococcus faecium)

L. bulgaricus ve Str. thermophilus bakterilerinin EPS oluşturma yetenekleri Kılıç ve ark. (2003) tarafından belirlenmiştir. Her iki mikroorganizma tarafından oluşturulan EPS kalitatif ve kantitatif açıdan incelenmiştir. Besiyerinde $10^{8}-10^{9} \mathrm{KOB} / \mathrm{ml}$ düzeyinde gelişen $L$. bulgaricus IFR 2772 suşunun $268 \mathrm{mg} / \mathrm{L}$, Str. thermophilus IFR 859 suşununise 374 mg/L EPS ürettiği araştırmalar sonucunda tespit edilmiştir. Ancak araştırmada incelenen söz konusu bakteri türünün mukoz yapı oluşturma özelliği, bakterilerin gelişme ve çoğalmalarında uygulanan inkübasyon sıcaklığı ve süresi, gelişme ortamındaki besin maddelerinin zenginliği ile mutasyon oluşturabilecek etkenlere bağlı olarak değiştiği ve ortadan kalktığı, EPS oluşturmayan bir bakterinin ise koşullar uygun olduğunda bu polimeri sentezleyebildiği ortaya konmuştur. Salazar ark. (2009) yaptıkları çalışmada intestinal mikrofloradan izole ettikleri EPS üreticisi 21 adet suşu genetik olarak tanımlamışlardır. 16S rRNA dizi analizi sonucunda 11 adet Bifidobacterium türü ve 10 adet Lactobacillus türü tanımlanmıştır. En yüksek EPS miktarının ise $51,4 \mathrm{mg} / 100 \mathrm{~mL}$ olduğu rapor edilmiştir. Tarafımızdan yapılan çalışmada ise glukoz cinsinden en yüksek EPS üretiminin134,60mg $\mathrm{L}$ ile $L$. bulgaricus
(La24B) suşunda olduğu belirlenmiştir. EPS'ler viskoziteyi arttırıcı, yapıyı düzenleyici ve su bağlayıcı gibi fonksiyonel özelliklerinden dolayı süt ürünlerinde ticari stabilizatörlerin yerine alternatif olarak kullanılabilmektedir. Oldukça düşük konsantrasyonlarda üretilen EPS'nin bile yapıyı geliştirici etkisi olduğu belirlenmiştir (Soyuçok ve ark., 2016). Bu nedenle de yoğurt üretiminde EPS üreten bakterilerin kullanılmasına önem verilmelidir. Böylece hiçbir katkı maddesi kullanılmadan son ürünün tekstürel özelliğini arzu edilen şekilde değiştirilerek tüketicilerin intiyaç ve taleplerini karşılamak mümkün olabilir. Aynı zamanda EPS üreten LAB'nin kullanımı ile tüketicilerin sağlığı doğal yöntemlerle korunmuş olacaktır. EPS üretiminin genetik açıdan dayanıksızlığı endüstriyel uygulamalarda önemli bir problem oluştursa da, optimum fermantasyon koşullarının sağlanması ile bu sorunun önüne geçilebilmektedir. EPS'nin vizkoziteyi artırma derecesi kültür türleri arasındaki farklara, inkübasyon koşullarına, besiyerindeki katı madde miktarına ve viskozite ölçümlerine bağlıdır. 


\section{SONUÇ}

Gıda endüstrisinde LAB'nin kullanımı oldukça yaygındır. Ancak her suşun verimliliği ve kullanıldığı alan kendine özgüdür. Bu çalışmada, doğal floramıza ait genetik tanısı yapılmış bir kültür koleksiyonu elde edilerek, tanımlanmış bu bakterilerin EPS üretim özellikleri belirlenmiştir. Yapılan çalışma sonucunda en yüksek EPS üretimine sahip olan L. bulgaricus La24B, La38A, La4C, Lj40C, La14A ve Lj38A'nın yoğurt üretiminde başlatıcı/destek kültür olarak kullanılma potansiyellerinin bulunduğu ortaya konmuştur.

\section{TEŞEKKÜR}

Bu çalışma 2015 yılı TÜBiTAK 2209-A Üniversite Öğrencileri Araştırma Projeleri Destekleme Programı tarafından desteklenmiştir.

\section{KAYNAKLAR}

Akpınar, D., (2013). Fonksiyonel keçi yoğurdu üretiminde farklı başlatıcı kültürlerin kullanım imkanlarının araştırılması",MAKÜ-0149-YL-12, Mehmet Akif Ersoy Üniversitesi (Basılmamış Yüksek Lisans Tezi).

Çetinkaya, E., Ayhan, K. (2012). Mikrobiyolojide kullanılan bazı moleküler teknikler. Karaelmas Fen Ve Mühendislik Dergisi, 2(1): 53-62.

De Vuyst, L., De Vin, F., Vaningelgem, F., Degeest, B. (2001). Recentdevelopments in the biosynthesis and applications of heteropolysaccharides from lactic acid bacteria. International DairyJournal, 11(9): 687-707.

Duboc, P.,Mollet, B. (2001). Applications of exopolysaccharides in the dairy industry. International DairyJournal, 11(9): 759-768.

DuBois, M.,Gilles, K. A., Hamilton, J. K., Rebers, P. T., Smith, F. (1956). Colorimetric method for determination of sugars and related substances. Analytical chemistry, 28(3): 350356.

Faber, E. J.,Zoon, P., Kamerling, J. P., Vliegenthart, J. F. (1998). The exopolysaccharides produced by Streptococcus thermophilus Rs and Sts have the same repeating unit but differ in viscosity of their milk cultures. Carbohydrate research, 310(4): 269-276.

Folkenberg, D. M.,Dejmek, P., Skriver, A., Guldager, H. S., Ipsen, R. (2006). Sensory and rheological screening of exopolysaccharide producing strains of bacterial yoghurt cultures. International DairyJournal, 16(2): 111-118.

Gobbetti, M., De Angelis, M., Corsetti, A., DiCagno, R. (2005). Biochemistry and physiology of sourdough lactic acid bacteria. Trends in Food Science\&Technology, 16(1): 57-69.

Jensen, M. A.,Webster, J. A., Straus, N. (1993). Rapid identification of bacteria on the basis of polymerase chain reaction amplified ribosomal DNA spacer polymorphisms. Applied and Environmental Microbiology, 59(4): 945-952.
Kandler, O. (1986). Genus Lactobacillus Beijerinck 1901, Bergey's manual of systematic bacteriology, 2: 12091234.

Kılıç, S., Karagözlü, C., Akbulut, N., Mater, Y. (2003). L. delbrueckisubsp. bulgaricus ve Str. salivarius subsp. thermophilus'un eksopolisakkarit oluşturma özellikleri. Dünya Gıda, 8: 64-68.

Kıran, F., Osmanagaoglu, O. (2011). Laktik asit bakterilerinin (LAB) identifikasyonunda /tiplendirmesinde kullanılan moleküler yöntemler. Erciyes UniversityJournal of Institute of Science and Technology, 27(1): 62-74.

Kok, J.,Venema, G. (1988). Genetics of proteinases of lactic acid bacteria. Biochimie, 70(4), 475-488.

Lee, KS., Kim, DS. (1986). Microbiological characteristics of kefir cultures. Korean Journal of DairyScience, 8(4): 266274.

Mora, D.,Fortina, M. G., Nicastro, G., Parini, C., Manachini, P. L. (1998). Genotypic characterization of thermophilic bacilli: a study on new soil isolates and several reference strains. Research in Microbiology, 149(10): 711-722.

Patel, A.,Prajapat, J. B. (2013). Foodand health applications of exopolysaccharides produced by lactic acid bacteria. Advances in Dairy Research, 1-8.

Ruas-Madiedo, P.,Tuinier, R., Kanning, M., Zoon, P. (2002). Role of exopolysaccharides produced by Lactococcus lactissubsp. cremoris on the viscosity of fermented milks. International Dairy Journal, 12(8): 689-695.

Salazar, N.,Prieto, A., Leal, J. A., Mayo, B., Bada-Gancedo, J. C., de Los Reyes-Gavilán, C. G., Ruas-Madiedo, P. (2009). Production of exopolysaccharidesby LactobacillusandBifidobacteriumstrains of humanorigin, and metabolic activity of the producing bacteria in milk. Journal of DairyScience, 92(9): 4158-4168.

Soyuçok, A., Ekiz, T., Başyiğit Kılıç, G. (2016). Ekzopolisakkaritlerin özellikleri ve gıda sanayindeki önemi. Nevşehir Bilim ve Teknoloji Dergisi, 332-344.

Sudağıdan, M. 2007. 16S Internally transcribed spacer (ITS) polimeraz zincir reaksiyon- restriction fragment lenght polymorphism (16S-ITS PZR-RFLP) ile stafilokokların tür düzeyinde tanımlanması. 4.Uygulamalı Moleküler Mikrobiyoloji Kursu, İnönü Üniversitesi Turgut Özal Tıp Merkezi.

Udomsil, N.,Rodtong, S., Tanasupawat, S., Yongsawatdigul, J. (2010). Proteinase-producing halophilic lactic acid bacteria isolated from fish sauce fermentation and their ability to produce volatile compounds. International Journal of Food Microbiology, 141: 186-194.

Werning, M. L.,Notararigo, S., Nácher, M., de Palencia, P. F., Aznar, R., López, P. (2012). Biosynthesis, purification and biotechnological use of exopolysaccharides produced by lactic acid bacteria. In Foodadditive. InTech.

Yerlikaya, O. (2014). Laktik asit bakterilerinin tanımlanmasında kullanılan başlıca fenotipik yöntemler. Gıda ve Yem Bilimi - Teknolojisi Dergisi, 14: 9-22.

Yüksekdağ, Z. N.,\& Beyatlı, Y. (2009). Bazı laktik asit bakterilerinin fizyolojik, biyokimyasal, plazmit DNA ve protein profil özelliklerinin incelenmesi. Gıda Dergisi, 34(2): 9198. 